\title{
THE ROLE OF ENDOGENOUS RHYTHMS IN VERTICAL MIGRATION
}

\author{
By JoHN E. HARRIS, F.R.S. \\ Department of Zoology, University of Bristol
}

(Text-figs. I-5)

It is now more than 40 years since Esterly (1917) first demonstrated on Acartia that the diurnal vertical migration of plankton might be governed by an endogenous rhythm of activity, irrespective of external stimuli except for those due to gravity. Since that time, however, evidence has accumulated of the dominant effect of light on planktonic movement and the attention of nearly all recent workers has been concentrated on this as the main source of migration.

Observations in the field (Russell, 1927; Clarke, 1933) and in the laboratory (Harris \& Wolfe, I955) have demonstrated a clear correlation of the downward movement of many species in the morning with an increase of overhead illumination, and of the reverse upward movement at dusk with a corresponding decrease in surface illumination. Bogorov (1946) has reported measurements from polar seas which suggest that the vertical migration of several planktonic species, present in its characteristic form during the autumn when there is a typical diurnal rhythm of light intensity, is absent during the arctic summer, when there is little or no change in surface illumination through the $24 \mathrm{~h}$. No corresponding observations have been reported during winter months in polar seas.

Bogorov points out that the species studied during the arctic summer live at a characteristic depth, and must therefore be actively maintaining this depth against upwelling and downward currents which would tend to displace them. He therefore concludes, with earlier workers, that the organisms are maintaining themselves at a level with optimum light conditions.

This notion of an 'optimum' light intensity, first developed by Rose (1925) and very actively explored by Russell (1927) is not inconsistent with laboratory observations made much earlier by Ewald (1910) on Cladocera. An alternation of active upward swimming and active or passive downward movement determines upper and lower boundaries of distribution governed by light intensity; the notion of an optimum light intensity, albeit subject to adaptation, is clearly envisaged by Ewald.

Harris \& Wolfe (1955), by recording photographically the movements of a population in a tank of water filled with a dilute solution of Indian ink, 
showed that with a cyclical change in overhead light intensity it was possible to realize the complete cycle of vertical migration in the laboratory, irrespective of the period of the light cycle, provided it was not less than $2 \mathrm{~h}$. In these experiments, the mean depth of the population below the surface throughout the artificial 'day' remained at a position of constant light intensity.

In view of these and many other studies it seems unnecessary to invoke any endogenous rhythm to account for the observed facts of vertical migration, at least in so far as movements during daylight are concerned. There is, however, much evidence (see the review of Cushing, 195I, for details) of a second cyclical movement occurring during the hours of darkness, characterized by a midnight sinking and a dawn rise of the organisms.

This movement was also recorded by Harris \& Wolfe in their experiments on Daphnia magna and was explained by them on the basis of a photokinetic action of light. Low light intensities activated swimming movements without producing orientation in relation to the light source; a 'dawn rise' could therefore be produced by illuminating the apparatus from any direction, laterally or from below as well as overhead. Because of the vertical posture taken up by the animal during its passive sinking movements, the intermittent active swimming phases always tended to produce a rise towards the surface. Similarly, the experimental midnight sinking was brought about by a gradual cessation of swimming when the light source was extinguished. Grosser, Baylor \& Smith (1953) have ingeniously demonstrated, as Bidder (1929) had suggested many years earlier, that antennal sense organs are concerned in this geotactic orientation of swimming, and the significance of this characteristic sinking posture in all planktonic forms is now clearly evident.

It is of course possible to argue that the dawn rise is no more than a particular case of the organism moving upwards into its light optimum-inevitably upwards at this time because the light intensity even at the surface is less than this optimum. From a theoretical point of view this would be equivalent to saying that in the normal oscillation up and down on either side of this optimum, the upward movement is photokinetic in character and the downward is phototactic or at least differently determined. Harris \& Mason (1956) have in fact demonstrated a similar laboratory cycle of vertical migration in blinded Daphnia; in this case orientation to a light source is no longer possible.

Any downward movement in such eyeless animals is a simple passive sinking, and it would appear that an inhibition of swimming in the blinded animal occurs at the same critical light intensity as the orientation effect described by von Frisch \& Kupelwieser (I9I3), which leads to active downward swimming in the intact animal. This kind of double-assurance mechanism in Daphnia brings into line the pattern of vertical migration in species which are, and those which are not, capable of phototactic, i.e. oriented, responses.

Nothwithstanding the simplicity of this photokinetic interpretation of the 
midnight sinking and dawn rise, there is in the literature of the earlier field studies evidence which tends to discredit it. In particular, a 'dawn' rise often appears to occur before there can be any appreciable increase in light intensity, even allowing for the long dawn period before sunrise in high latitudes. The work of Esterly (I9I4), Kikuchi (1930) and Southern \& Gardiner (I932) provide examples of this phenomenon; it becomes therefore of some interest to discover whether there is any other stimulus to activity responsible for this phase of the vertical migration cycle.

Such an influence could be provided by the endogenous rhythm of activity postulated by Esterly (I9I7). Hardy \& Paton (I947) found some evidence for a rhythm of this kind in field experiments on Calanus. Moore \& Corwin (1956) used a mathematical technique to investigate the relationship between light intensity, temperature and pressure (depth) in the distribution of siphonophores in the Florida current; they found it necessary to postulate a diurnal rhythm in the strength of responses to these stimuli in order to account for their results. Rimet (1960) has provided a limited amount of experimental evidence for a diurnal cycle of photopositivity in Daphnia pulex. The experiments described in the present paper were designed to examine the presence of rhythms of activity, as distinct from rhythms of sensitivity, in animals kept continuously in darkness.

\section{EXPERIMENTAL METHODS}

The photographic technique employed earlier (Harris \& Wolfe (1955); Harris \& Mason (1956)) was adapted to study the distribution of animals in a small tank kept in continuous darkness over long periods. Studies were undertaken with Daphnia magna Straus at Bristol and with Calanus finmarchicus (Gunnerus), var. helgolandicus Claus, at Plymouth. Indian ink suspensions were of course not necessary in these experiments, but as observations were continued over periods of several days some difficulties were anticipated over problems of food and oxygen supply.

Aeration of the tank was clearly out of the question, though an early attempt was made to aerate a section isolated from the main photographic area by a vertical sheet of bolting silk. This method failed to eliminate currents in the non-aerated portion and since, even in the absence of aeration, counts of living animals present on successive days showed little mortality over a period of 4 or 5 days, experiments were finally conducted without aeration or food in the tank.

Strictly speaking it is incorrect to say that the animals were studied in continuous darkness, since they were illuminated at each photographic exposure. This illumination was provided at hourly intervals by a single flash of deep red light. Many experiments in earlier work had shown that this flash had no effect on the distribution of the animals unless it was repeated at intervals of less than I min. Furthermore, since the flash was repeated hourly throughout the experiment, it could not be expected to influence any rhythmical behaviour which might be observed.

The experiments on Daphnia were done in a darkened laboratory; the photographic gear and the tank were housed in the laboratory within a separate light-tight frame. Continuous temperature records were taken throughout several of the experiments and no systematic temperature variation was recorded; it was therefore not 
thought necessary to instal any elaborate method of temperature control. In Plymouth, similar experiments on Calanus were done in a light-tight box built in the cellar and therefore even less subject to temperature change.

In all cases about 50-100 animals were employed in each experiment, contained in a tank of about 21 . capacity. Daphnia magna were taken from supply tanks which had previously been kept in ordinary daylight for several days; Calanus were obtained in all cases from tow-nettings brought in on the same day that the experiment was started. Almost all the animals used in studies with both these species were adult females; a few males of Calanus were occasionally present and during the winter months it is likely that a substantial proportion of stage $\mathrm{V}$ (sex unknown) was present.

\section{RESULTS}

The diurnal cycle in Daphnia magna

Fig. I shows the movement of the centre of mass of a Daphnia population kept in darkness over a period of 4 days. There is clear evidence of a diurnal cycle, the population starting to move up towards the top of the tank during the night, attaining a maximum height about 4.00 p.m. Following this there was a fairly rapid descent to the lowest levels, reached two or three hours after the time of sunset. The mean daily movement is indicated by a different method in Fig. 2, while Fig. 3 shows the actual distribution at 4.30 p.m. and I0.30 p.m. representing approximately the two extreme states of distribution of the population.

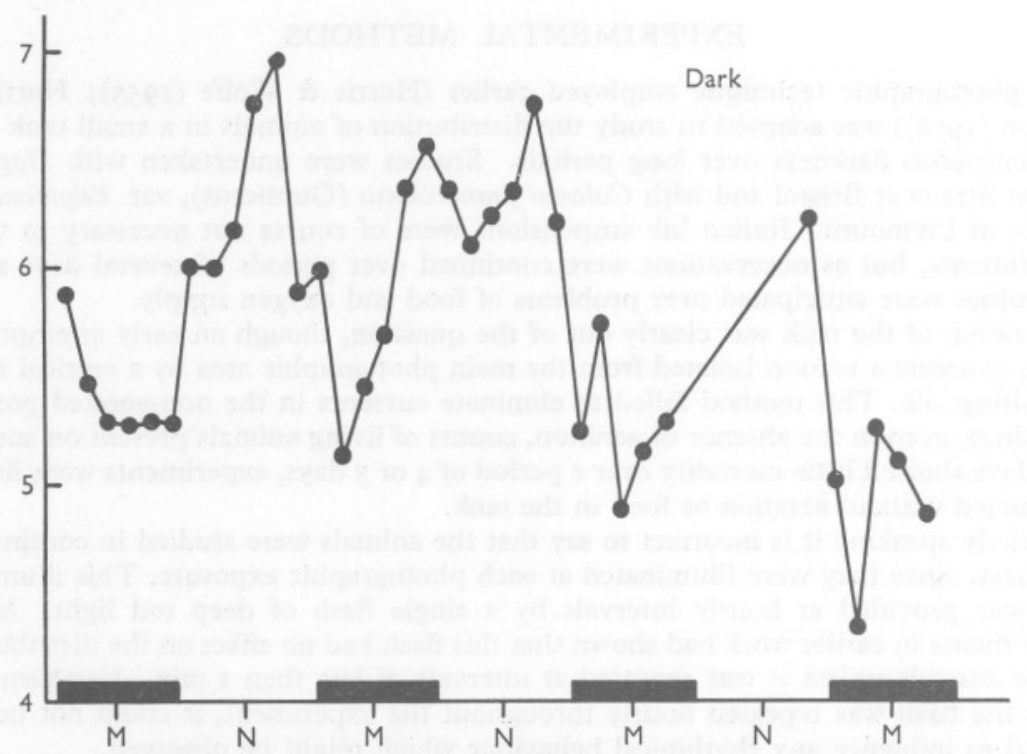

Fig. I. Vertical position of the mean of a population of Daphnia magna in darkness. Ordinate measured in arbitrary units each equal to $\mathrm{r} / \mathrm{IO}$ of the height of water in the tank. Abscissa: time of day over 4 successive days. The black rectangle indicates the period between sunset and sunrise. M, Midnight; N, noon. 
The rhythm indicated is almost precisely a $24 \mathrm{~h}$ one, and the fact that it is not simply brought about by small cyclical changes in external factors such as temperature is confirmed by a similar experiment carried out under conditions of constant illumination. While population movement was less pronounced under these conditions, there was a residual rhythmical element at a period of approximately $28 \mathrm{~h}$ (Fig. 4). This lengthening of the period in presence of light is of course a characteristic feature of biological clocks of this type.

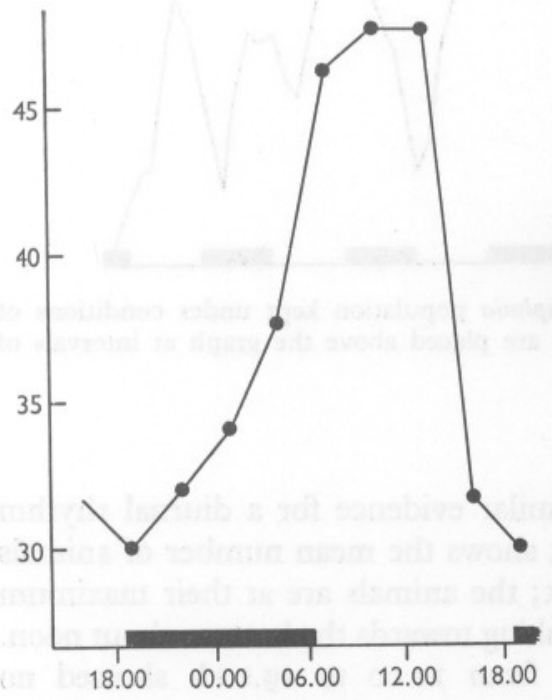

Fig. 2

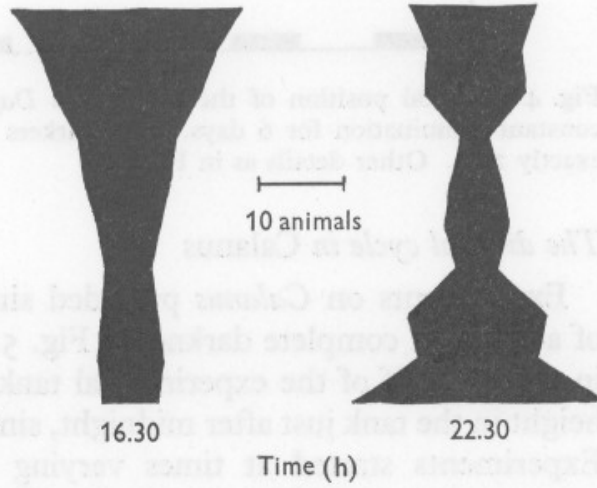

Fig. 3

Fig. 2. Average number of Daphnia in top half of the experimental tank. The figures are averaged over 4 successive days.

Fig. 3. Vertical distribution of Daphnia at $16.30 \mathrm{~h}$ and $22.30 \mathrm{~h}$ on the 2 nd day of the experiment illustrated in Fig. $\mathbf{I}$.

Whilst all experiments with Daphnia showed the same general pattern of movement, there was some indication that the movement downward, which takes place in the daylight hours, varied in time in relation to the actual time of day at which the experiment was started-i.e. if the experiment was started early in the day the first and all subsequent descents took place earlier than if the start had been delayed. No similar variation occurred in the time of the night rise; this began about 8.00-9.00 p.m., irrespective of the time of day at which the animals had first been placed in the darkened experimental tank. Further work would be required to confirm these results, which suggest that the rise and fall are determined by two independent phase-settings in relation to the underlying clock mechanism. 


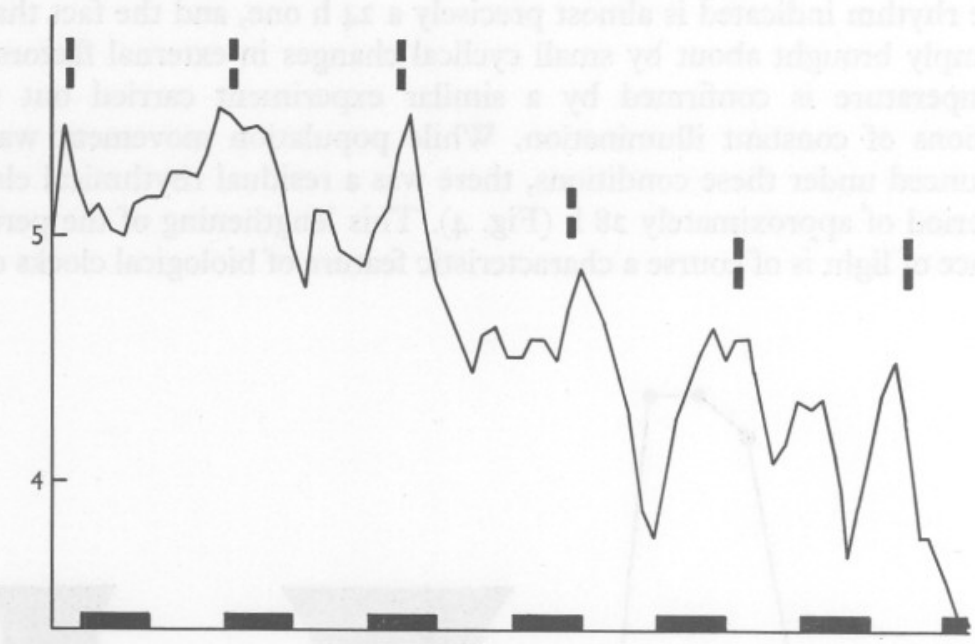

Fig. 4. Vertical position of the mean of a Daphnia population kept under conditions of constant illumination for 6 days. The markers are placed above the graph at intervals of exactly $28 \mathrm{~h}$. Other details as in Fig. I.

\section{The diurnal cycle in Calanus}

Experiments on Calanus provided similar evidence for a diurnal rhythm of activity in complete darkness. Fig. 5 shows the mean number of animals in the top half of the experimental tank; the animals are at their maximum height in the tank just after midnight, sinking towards the bottom about noon. Experiments started at times varying from 10.00 to $19.00 \mathrm{~h}$ showed no systematic variation in the times of maximum and minimum height (see Table $\mathrm{I}$ ). The time of maximum activity in $\mathrm{I} 3$ such experiments ranged from $2 \mathrm{r} .30 \mathrm{~h}$ to $02.00 \mathrm{~h}$ with two exceptions, both in April, when the rhythm was not very clearly defined; the mean is close to midnight. The corresponding time for minimum activity was less clearly marked, ranging from $05.00 \mathrm{~h}$ to $\mathrm{I} 8.00 \mathrm{~h}$; the mean time of minimum activity was approximately at noon.

\section{Seasonal variation in the pattern of response}

During several years of work with Daphnia magna in the laboratory, it has become evident that the results of experiments such as those described above, as well as of the earlier types of experiment with cyclical intensity changes in an overhead light course, have been subject to unexpected variation. At times we have had quite unaccountable failures, the animals showing no tendency to leave the bottom of the tank, although the conditions were in all respects identical with those of other completely successful experiments. This would normally lead to a suspicion of the validity of the whole investigation, were it not for the fact that the success or failure of the experiment seemed to be an 
'all-or-nothing' feature: either it worked perfectly giving predictable responses or it failed equally completely. Only after some time did it become possible to suggest in Daphnia that the differences were perhaps related to the time of year at which the rather infrequent experiments were carried out. (The fact that most of the experiments were of necessity concentrated in the University vacations made the systematic nature of these variations rather more obscure.) If, however, the effect were seasonal in character, it clearly could best be looked for in a marine form such as Calanus, where seasonal patterns of vertical distribution are strongly marked.

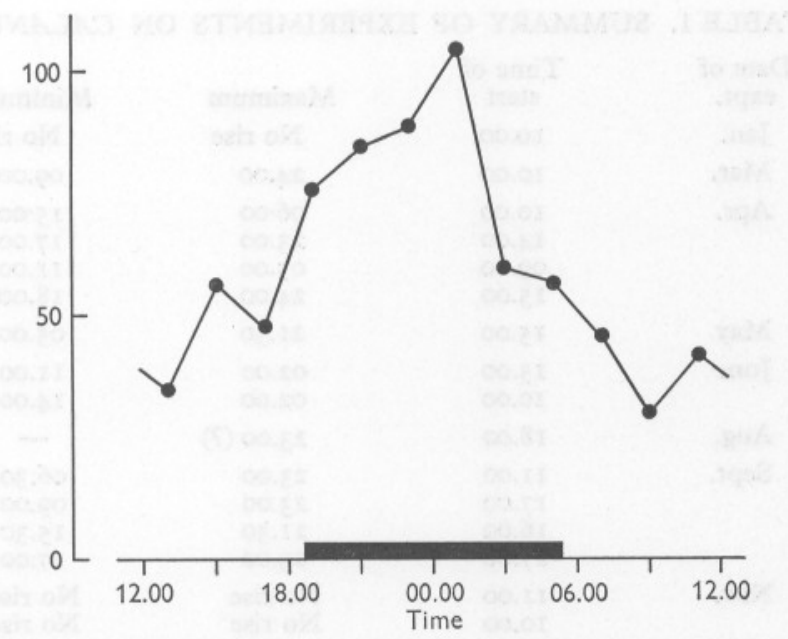

Fig. 5. Diurnal rhythm of Calanus in darkness. Ordinate: number of animals in the top half of the tank. Each point represents the sum of two observations one hour apart; the figure so obtained is averaged over the four days of the experiment. Abscissa as in Fig. 2.

Thanks to the improvement of the automatic features of the photographic gear, and even more to the untiring assistance of Dr E. D. S. Corner at Plymouth, it has been possible over the last two years to carry out experiments throughout the year, the film records being collected and examined at leisure in Bristol. These records have shown that the cyclical vertical movement of Calanus in darkness varies in a more or less regular and predictable fashion.

Because of difficulties of collection of the animals in the winter months, experiments during this time of year have been more limited than at other seasons, but over a period of three years in all, experiments carried out during the period November to January have shown no appreciable rhythm of vertical movement in Calanus, even though the animals have been perfectly healthy and mobile at the end of the experiment. In actual fact, a larger proportion of the animals survived at the end of the experimental 
period of 5-6 days during the winter months than at the height of summer. Table I shows a selection of such experiments at different times of year.

The experiment carried out in March was particularly interesting in this respect. All the animals tended to remain at the bottom of the tank for the first 2 days, after which the diurnal rhythm developed in its characteristic form. One might perhaps speculate that this time of year represents the critical period for the transition, and that the higher temperatures in the experimental tank had triggered the rhythm after a certain delay which is itself of some interest.

\begin{tabular}{|c|c|c|c|}
\hline $\begin{array}{l}\text { Date of } \\
\text { expt. }\end{array}$ & $\begin{array}{l}\text { Time of } \\
\text { start }\end{array}$ & Maximum & Minimum \\
\hline Jan. & 10.00 & No rise & No rise \\
\hline Mar. & 10.00 & 24.00 & 09.00 \\
\hline Apr. & $\begin{array}{l}10.00 \\
14.00 \\
09.00 \\
15.00\end{array}$ & $\begin{array}{l}06.00 \\
23.00 \\
05.00 \\
24.00\end{array}$ & $\begin{array}{l}15.00 \\
17.00 \\
11.00 \\
18.00\end{array}$ \\
\hline May & 15.00 & 21.30 & 05.00 \\
\hline June & $\begin{array}{l}\text { I5.00 } \\
10.00\end{array}$ & $\begin{array}{l}02.00 \\
02.00\end{array}$ & $\begin{array}{l}11.00 \\
14.00\end{array}$ \\
\hline Aug. & 18.00 & $23.00(?)$ & - \\
\hline Sept. & $\begin{array}{l}\text { I1.00 } \\
17.00 \\
16.00 \\
17.00\end{array}$ & $\begin{array}{l}23.00 \\
23.00 \\
21.30 \\
23.00\end{array}$ & $\begin{array}{l}06.30 \\
09.00 \\
15.30 \\
17.00\end{array}$ \\
\hline Nov. & $\begin{array}{l}\text { II. } .00 \\
10.00\end{array}$ & $\begin{array}{l}\text { No rise } \\
\text { No rise }\end{array}$ & $\begin{array}{l}\text { No rise } \\
\text { No rise }\end{array}$ \\
\hline Dec. & $\begin{array}{l}13.00 \\
\text { Mean }\end{array}$ & $\begin{array}{c}\text { No rise } \\
24.23\end{array}$ & $\begin{array}{c}\text { No rise } \\
\text { I2.20 }\end{array}$ \\
\hline
\end{tabular}

\section{Visual observations of the behaviour of Calanus in 'darkness'}

There is one very significant feature of all the photographs taken in this long series of experiments. It was exceedingly rare to find an animal in any posture other than the normal one associated with swimming upwards or passive sinking. This was true not only for those animals at the top of or in the body of the tank but even of those which were 'resting' on the bottom. Visual observations of such a tank in infra-red light, using an image converter, confirmed this feature of the photographs. Those Calanus which were (in the film) apparently resting on the bottom were in fact 'bouncing' gently on their tails with the body pointing vertically upwards, the antennae held widely spread in the normal sinking attitude. Those which swam in the main body of the tank were doing so by the typical 'hop and sink' alternation: short bursts of swimming alternated with periods of passive sinking. Only very occasionally, when contact with the water surface or the walls of the tank produced a violent tactile stimulus, was the animal seen to change its attitude 
and swim actively in a horizontal or downward direction; this situation is only likely to be encountered in the sea when a Calanus makes contact with some other organism, eliciting a characteristic avoiding reaction.

If these same features are shown by Calanus in darkness in its natural environment, we can say that the body of animals will be at almost all times in a vertical attitude. In the absence of sensory mechanisms for orientation (e.g. direction of light) a long continued burst of active swimming could theoretically take it in any direction; the short alternating spells of swimming and sinking, however, will take place entirely in the vertical direction. If they are of equal extent, the animal will remain at a constant depth; if swimming predominates, it will gradually rise towards the surface; if the sinking phase predominates the animal will descend. Changes in activity will therefore be reflected as a whole in rising or sinking of the population and in this respect a diurnal cycle of activity will result in a cyclical vertical displacement of the population.

Observations with the infra-red telescope did in fact lead to the conclusion that the distance moved upwards by the animal during the swimming phase was approximately equal to that of the downward movement of the corresponding passive sinking - in other words that over a limited period of observation the animal tended to remain in roughly the same horizontal plane. The experimental arrangement did not, however, permit the use of a large field of observation, so that it was not possible to employ a very tall tank. Over a period of several minutes, contact with the tank walls or with the water surface tended to obscure this equilibrium.

All one can say, therefore, is that in darkness the alternation of upward movement and downward sinking is in a state of approximate balance; a relatively small change in activity of the animal will therefore produce long term displacements which might be upwards or downwards in direction; these are the changes which are presumably reflected in the altered distribution of the animals in the photographic film.

\section{CONCLUSIONS}

It is important to emphasize at the outset that the experiments described above do not reproduce in the laboratory a vertical migration in the same sense as did those in the earlier studies (Harris \& Wolfe, 1955; Harris \& Mason, 1956). In an Indian ink suspension, illuminated from above, there exists a steep vertical gradient of light intensity which was found to determine the level in the tank about which the position of any individual animal oscillates. In relation to light intensity as a determining factor, this level in the experimental tank corresponded to a substantial depth in sea water (or fresh water), and movement of the animal up or down by only a few centimetres in the tank represented a migration of several tens of metres in sea 
water. The vertical distribution of a population of animals in such an experimental tank, as in nature, shows the characteristic 'kite' form under these circumstances.

Where however we are concerned with movements taking place in darkness the above considerations do not apply. In a small tank, $20 \mathrm{~cm}$ in height, there is no graded factor limiting the extent, and only gravity determining a direction, of movement. (Pressure changes, far greater than those which are involved here, were found to produce no effect on the movement of Daphnia or Calanus.) The distribution of animals in the darkened tank is always of an 'hour-glass' form (Fig. 3), reflecting a proportion of animals which are more active, thus tending to concentrate near the top of the tank, and a further group of less active forms, tending to accumulate near the bottom. What is therefore being determined by the distribution is the extent to which the animals, at the particular moment of taking the photograph, are more active and tending to rise, or more passive and tending to sink.

The experiments described in the present study have clearly demonstrated the existence, in two different genera of planktonic crustacea, of a daily rhythm in this locomotor activity. In darkness, this rhythm occurs as a $24 \mathrm{~h}$ cycle and the fact that the period is changed to $28 \mathrm{~h}$ in Daphnia under conditions of continuous illumination is strong support for the idea that we are dealing with another of the well-known examples of 'built-in' biological rhythms of the organism. For descriptive convenience this will be referred to in what follows as the intrinsic rhythm of activity, without implying that it is determined only by internal factors. It might for example be a persistent product of the daily cycle of light and darkness experienced by the animals before they were brought into the laboratory, though in view of the enormous volume of experience which has now accumulated on other animals it seems reasonable to ascribe it to some kind of internal biological clock.

While both Daphnia and Calanus exhibit this intrinsic rhythm of activity in darkness, the phasing of the cycle differs in the two animals. Both show increasing activity during the evening hours but whereas the maximum is reached in Calanus at midnight, activity goes on increasing in Daphnia from $2 \mathrm{r} .00 \mathrm{~h}$ until the following afternoon. It is not proposed to try to offer an explanation of this difference, though it may be pointed out that the feeding habits of the two animals are very different. Calanus feeds presumably in the photosynthetic layer which it would occupy during the hours of dusk and darkness, while Daphnia magna is almost a detritus feeder, living in shallow ponds where much of its food will exist in a rich organic layer at and near the bottom.

We know little of any pattern of diurnal migration of Daphnia magna in the field, though Ringelberg (I96I) has recently made some interesting observations which suggest that this is present. In Calanus, however, the cycle is well known, and it is perhaps significant that Hardy \& Paton (I947) demon- 
strated-on the basis of admittedly few observations with the plankton tubethe existence of a tendency to swim upwards during the early part of the night. These observations appear to confirm the results of our laboratory studies.

It is suggested that the existence of an intrinsic rhythm of activity could account for those cases where the so-called 'dawn rise' occurs during the night hours actually before any increase in overhead illumination could be present. If this view be accepted a complete theoretical pattern of vertical migration could be visualized in the following form.

At midday, the depth of the organism is governed by phototactic responses and is determined entirely by the light intensity; the vertical distribution of the population about this optimum depth is of the typical kite form. As daylight diminishes, the 'kite' shifts towards the surface until the light intensity in the surface layers falls below this optimum value. Phototactically controlled downward movements will now cease, but for some time after, the light will be sufficient for photokinetic activation to maintain the organism in or near the surface. As the light fails, however, this effect wears off and the animals begin to sink-the so-called midnight sinking. The population distribution during this phase would probably show a more or less uniform vertical column, reflecting a gradual recruitment of more and more animals from the surface into the continuously sinking population.

During the hours of darkness, however, the intrinsic rhythm of activity is able to become manifest; if the phasing of this rhythm is appropriate, a rise towards the surface could occur at any time-well before true dawn. The appearance of dawn itself would produce photokinetic activation in the population; this effect could reinforce and would finally predominate over the intrinsically determined rhythm so that the population, now concentrated into a wedge shaped distribution with the bulk of the animals nearer the surface, would tend to accumulate there. Further increase of light intensity at or after sunrise would initiate phototactic or inhibitory responses; the population would begin to move actively downwards in the typical kite distribution, following the light intensity down to its characteristic mid-day depth.

The description given above is obviously hypothetical, but it appears to be justified by the physiological characteristics of the animals as observed in the laboratory and to reconcile many variations of pattern encountered in field observations. It supplements the theoretical picture given earlier by Harris \& Wolfe (1955) by adding the effect of the intrinsic rhythm and in so doing it provides an explanation not only for cases of a false dawn rise but also for one other curious and hitherto unpublished feature of our earlier experiments.

In these experiments with Daphnia, it was occasionally found difficult or even impossible to start the migration cycle in the indian ink suspension. This could happen when the suspension of ink was too dense, or the animals had 
been left in darkness too long before the experiment was started. Apparently the light intensity at the bottom of the tank was too low to bring about photokinetic activation and thus to move the animals up into a region where the normal phototactic depth control could begin to operate. When this happened, supplementary illumination from the side, or stirring the tank, always started the cycle successfully. Such results were of course disregarded in the original work, but it now appears that they may have considerable relevance to natural conditions.

It is not difficult to imagine conditions, e.g. in northern latitudes or under severe and continuous overcast during the morning hours, in which an animal could sink beyond the range of possible photokinetic activation and would then fail to take part in the normal migration cycle. Such a situation could not arise however if a diurnal intrinsic rhythm of activity provided for upward movement at critical times of the day; the selective value of such a mechanism would be considerable.

The fact that the intrinsic rhythm is apparently seasonal in its operation, being absent from animals experimented on during the winter months, is of considerable importance. It is well known that Calanus helgolandicus spends the winter months in deeper waters and that during this period the diurnal cycle of vertical migration is absent-not only in the stage V copepodite but also in those adults which overwinter in the population.

Carlisle \& Pitman (I96I) have likened this seasonal inactivation in Calanus to the diapause of insects, and have recently described correlated changes in the activity of certain neurosecretory cells in the brain. The suspension of the reproductive cycle is clearly the main manifestation of this inactivation, but it is not altogether far-fetched to assume that one of the concomitant effects could be the switching-off of the biological clock which determines the intrinsic activity rhythm. The participation of hormonal mechanisms in these biological clocks is implicit in much of the literature on the subject, and the interesting single experiment in March, reported above, is suggestive. The effect of increased temperature in activating hormonal mechanisms is already well established, and the delay in development of the intrinsic rhythm in this experiment is consistent with the intervention of a chemical or morphological process of maturation preceding activation of the rhythm.

It does not of course follow that increase of temperature is the natural factor involved in breaking the 'diapause' of Calanus in the spring, though the occurrence of several generations in the annual reproductive cycle suggests that some extrinsic factor is involved. If, as suggested by Yaschnov (I96I), Calanus helgolandicus is in fact a Mediterranean form, the northern stocks being continually recruited from the parent stock, it is not altogether surprising to encounter a significant effect of temperature on the seasonal activity in what Yaschnov would consider to be the fringe area of its distribution. In this connexion, Hure (1955) has reported a seasonal pattern of vertical 
distribution in the Adriatic which is completely different from that shown in northern waters.

The work on Calanus described in this paper was begun during the tenure by the writer of the Ray Lankester Investigatorship, to the Trustees of which he is greatly indebted for the opportunity thus provided. To the Director and staff of the Plymouth laboratory he is grateful for much valuable help and advice; in addition he is indebted particularly to M. S. Gillett and K. Wood for technical assistance at Bristol.

\section{SUMMARY}

Photographic recording at hourly intervals of a group of animals contained in a small tank kept in continuous darkness has revealed a $24 \mathrm{~h}$ cycle of locomotor activity in Daphnia magna and in Calanus helgolandicus.

A change in periodicity of the rhythm in Daphnia kept under continuous illumination suggests that the cycle is not determined by external stimuli.

The phasing of the cycle differs in the two animals, but in both there is an increase in activity during the hours of darkness.

In Calanus and possibly also in Daphnia, the cycle of activity is absent in the winter months.

Observations of Calanus in infra-red light confirm that a vertical 'hop and sink' alternation is typical of these animals in darkness.

The results are considered in relation to earlier field observations of a false dawn rise in many forms, and to the seasonal differences in the vertical distribution of Calanus helgolandicus. Hormonal control of the biological clock would account for the general pattern of laboratory and field observations.

\section{REFERENCES}

BIDDER, G. P., 1929. Geotropism and antennae. Nature, Lond., Vol. I23, p. 799.

Bogorov, B. G., I946. Peculiarities of diurnal vertical migrations of zooplankton in polar seas. F. mar. Res., Vol. 6 (i), pp. 25-32.

Carlisle, D. B. \& Pitman, W. J., I96r. Diapause, neurosecretion and hormones in Copepoda. Nature, Lond., Vol. 190, p. 827.

Clarke, G. L., 1933. Diurnal migration of plankton in the Gulf of Maine and its correlation with changes in submarine irradiation. Biol. Bull., Woods Hole, Vol. 65 , pp. $402-36$.

Cushing, D. H., I95I. The vertical migration of planktonic Crustacea. Biol. Rev., Vol. 26, pp. 158-89.

ESTERLY, C. O., I9I4. The vertical distribution and movements of the Schizopoda of the San Diego region. Univ. Calif. Publ. Zool., Vol. 13, pp. 123-145.

ESTERLY, C. O., I9I7. The occurrence of a rhythm in the geotropism of two species of plankton Copepods when certain recurring external conditions are absent. Univ. Calif. Publ. Zool. Vol. I6, pp. 393-400. 
EWALD, W., I910. Über Orientierung, Lokomotion und Lichtreaktionen einiger Cladoceren und deren Bedeutung für die Theorie der Tropismen. Biol. Zbl., Bd. 30, pp. I, 49, 379, 385 .

FRISCH, K. vON \& KUPELWIESER, H., I913. Über den Einfluss der Lichtfarbe auf die phototaktischen Reaktionen niederer Krebse. Biol. Zbl., Bd. 33, pp. 517-52.

GROSSER, B. I., BAYLOR, F. R. \& SMITH, F. E., I953. Analysis of geotactic responses in Daphnia magna. Ecology, Vol. 34, pp. 804-5.

HaRdy, A. C. \& Paton, W. N., 1947. Experiments on the vertical migration of plankton animals. F. mar. biol. Ass. U.K., Vol. 26, pp. 467-526.

Harris, J. E. \& MAson, P., I956. Vertical migration in eyeless Daphnia. Proc. Roy. Soc. B, Vol. 145, pp. 280-90.

Harris, J. E. \& Wolfe, U. K., I955. A laboratory study of vertical migration. Proc. Roy. Soc. B, Vol. I44, pp. 329-54.

HURE, J., I955. Distribution annuelle verticale du zooplancton sur une station de l'Adriatique meridionale. Acta adriat., Vol. 7, pp. I-72.

KIKUCHI, K., 1930. Diurnal migration of plankton Crustacea. Quart. Rev. Biol., Vol. 5, pp. 189-206.

Moore, H. B. \& CoRwin, E. G., 1956. The effects of temperature illumination and pressure on the vertical distribution of zooplankton. Bull. mar. Sci. Gulf Carib., Vol. 6, pp. 273-87.

Rimet, M., I960. Persistances rythmiques dans le phototropisme de Daphnia pulex de Geer. Année Biol., Sér. 3, T. 36, pp. 189-98.

RINGELBERG, J., I96I. A physiological approach to an understanding of vertical migration. Proc. Kon. Ned. Akad. v. Wetensch. Amst., Ser. C, Vol. 64, pp. 489-500.

Rose, M., 1925. Contribution à l'étude de la Biologie du Plankton. Le problème des migrations verticales journalières. Arch. Zool. exp. gén., T. 64, pp. 387-542.

Russell, F. S., I927. The vertical distribution of plankton in the sea. Biol. Rev., Vol. 2, pp. 213-62.

SOUTHERN, R. \& GARDINER, A. C., I932. The diurnal migrations of the Crustacea of the plankton in Lough Derg. Proc. R. Irish. Acad., Vol. 40, pp. I2I-59.

YASchNov, V. A., I96r. Vodnye massy i plankton. I. Vidy Calanus finmarchicus s.l. kak indikatory opredelennykh vodnykh mass. (Water masses and plankton. I. Species of Calanus finmarchicus s.1. as indicators of definite water masses.) Zool. Zh., Vol. 40 (9), pp. I3I4-34. 